\title{
INTERRELATIONSHIP BETWEEN CONTROL PARAMETERS AND TUMOR/BONE CONDITIONS FOR EXTERNAL ULTRASOUND HYPERTHERMIA
}

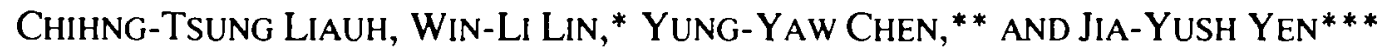 \\ Department of Mechanical Engineering, Kun Shan University of Technology, Tainan, \\ ${ }^{\star}$ Institute of Biomedical Engineering, ${ }^{\star}$ Department of Electrical Engineering,

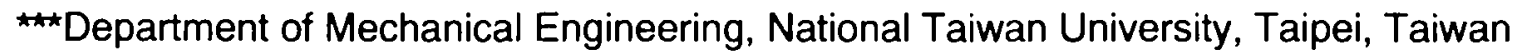

\begin{abstract}
The purpose of this paper is to examine the relationship between the control parameters and the tumor/bone conditions, and also to determine the domain determined by the treatable tumor size and tumor depth for an external ultrasound hyperthermia. This work employs computer simulation programs based on a simplified model of a scanned ultrasound transducer power deposition, the steadystate bio-heat transfer equation, and a search algorithm. The low bounds of SR (specific absorption rate ratio) and $f \cdot S R$ ( $f$ : ultrasound frequency) are determined based on the temperature distributions for large ranges of blood perfusion and ultrasound frequencies. These low bounds of SR and $f \cdot S R$ are then used to investigate the relationship between the control parameters and the tumor/bone conditions and to determine the treatable domain. The control parameters considered are the acoustic window size, ultrasound frequency; and the tumor/bone conditions are tumor size, tumor depth, and the depth of post-target bone. Simulation results demonstrate that a) the low bounds of SR and $f \cdot S R$ are functions of blood perfusion; $b$ ) the ultrasound frequency to obtain the largest treatable tumor size depends on the tumor depth and the depth of post-target bone, however it is independent of the acoustic window size; and c) the treatable domain is proportional to the acoustic window size and the depth of post-target bone, and a proper frequency can result in a larger treatable domain. The results of this study can be a guideline for designing an optimal ultrasound heating system, arranging the transducers, and implementing further treatment planning for the external ultrasound hyperthermia.
\end{abstract}

Biomed Eng Appl Basis Comm, 2001 (August); 13: 199-212.

\section{INTRODUCTION}

Owing to the physical characteristics of acoustic propagation in tissues, the ultrasound energy can be

Received: July 10, 2001; Accepted: Aug. 5, 2001

Correspondence : Win-Li Lin, Ph.D.

Institute of Biomedical Engineering, College of Medicine, National Taiwan University, No.1, Sec. 1, Jen-Ai Road, Taipei, Taiwan

E-mail: kcju(aipmc.ee.ntu.cdu.tw focused to specific depths in soft tissues. To treat deep-seated tumors, focused or multiple overlapping fields must be used. The general approaches evaluated in the laboratory and/or in clinical trials are: a) single or multiple beams directed or focused onto the tumors (Fessenden et al 1984, Seppi et al 1985, Hynynen et al 1983, Diederich et al 1992, Svensson et al 1992, Lin et al 1999a); b) a well-focused beam scanned rapidly across the tumor to generate an enhanced temperature distribution (Lele and Parker 1982, Lele 1984, 1989, Hynynen et al 1987. Hunt et al 1991, Dutton et al 1996); and c) a phased array excited by independent sources with defined phases and amplitudes (Cain and 
Umemura 1986, Cain et al 1987, McGough 1996). The above approaches attempted to select the ultrasound frequency and arrange the system parameters to obtain an appropriate power deposition to heat a deep-seated tumor, and also to use surface cooling water to reduce the skin temperature. The ultrasonic beam must enter through a large skin area and then converge into a much smaller target area in order to induce a higher temperature at the desired depth (Hynynen 1990). Therefore, the above systems would overheat the in tervening normal tissue between the skin and the target volume during the treatments when the acoustic window size is insufficient for a specific tumor. The appropriately minimum diameter of acoustic window depends on the tumor size, tumor depth, ultrasound frequency, etc (Lin et al 1999b).

There have been also several studies showing selective heating of the post-target bone surface during sonication with non-focused physiotherapy transducers operating at $1 \mathrm{MHz}$ (Nelson et al 1950, Lehmann et al 1966, 1967). Similar hot spots also appear during ultrasound hyperthermia when weakly focused, low frequency, single beam systems are used to heat tissues in front of bones (Marmor et al 1979, Hynynen and DeYoung 1988). The low intensity at the bone surfaces can be achieved in many cases with multiple focused beams, higher frequencies, or more sharply focused transducers (Hynynen and DeYoung 1988). Since a hot spot is mainly caused by energy absorption in the bone, it can also be reduced by decreasing the amount of energy transmitted into the bone through the interface. By increasing the incident angle of ultrasound beam (Davis and Lele 1987), the energy into the bone can be effectively reduced. During external ultrasound hyperthermia, it is also necessary to avoid overheating the post-target bone behind the tumor. Owing to the high absorption of ultrasound by bone, a sufficiently low level of ultrasound intensity should be used to avoid causing high temperature on the post-target bone and/or discomfort for the patient.

In order to overcome the effect of ultrasound attenuation in the soft tissue and the overheating problem on the post-target bone, a convolution power deposition with a convergent-divergent cone shape should be formed to obtain an appropriate heating. Scanned, focused ultrasound heating systems (Lin et al 1992, 1999a, Dutton et al 1996) can produce a convolution power deposition close to this ideal shape by scanning the ultrasound beams with appropriate scan parameters (tilt and rotation angles, scan radius, focal depth, and input power level). In addition, twodimensional arrays of transducers (Cain and Umemura 1986, Cain et al 1987, McGough 1996) can yield such a power deposition by controlling the amplitude and phase of each array element. The present work employs the steady-state bio-heat transfer equation, the above simplified model of the ultrasound power depo- sition, and a search method to examine the distributions of temperature and $S A R$ (specific absorption rate) ratio. To investigate the interrelationship between control parameters and tumor/post-target bone conditions, suitable low bounds of $S R$ (specific absorption rate ratio) and $f \cdot S R$ ( $f$ : ultrasound frequency) are determined based on the temperature distributions for large ranges of blood perfusion and ultrasound frequencies. The results show that the low bounds of $S R$ and $f \cdot S R$ are functions of blood perfusion. The appropriate frequency and the acoustic window size required for a given set of tumor/post-target bone conditions have been investigated based on the low bounds of $S R$ and $f \cdot S R$. Furthermore, the treatable domain of tumor size and tumor depth has also been studied when the acoustic window size, ultrasound frequency, and the depth of post-target bone are given.

\section{METHODS}

\subsection{Ultrasound Power Deposition}

The deposition of ultrasound energy is modeled as two truncated cones with a convergent/divergent shape as shown in Figure 1 . The left side with a diameter of $d(0)$ is regarded as the acoustic window for the ultrasonic beam, and the right side with a diameter of $d\left(z_{b}\right)$ is regarded as the region where the ultrasound beam intersects on the bone behind the tumor, referred to as the post-target bone in the following study. The narrowest region with a diameter of $d\left(z_{t}\right)$ is regarded as the focal zone and, beyond this zone, the ultrasonic beam then diverges. This type of power deposition can produce an appropriate temperature distribution for heating a deep-seated tumor, while the acoustic window for the ultrasound beam is sufficiently large to overcome the ultrasonic attenuation caused by the soft tissue (Hynynen et al 1987, Lin et al 1999b). This type of power deposition can also avoid overheating the region beyond the tumors because of the ultrasonic attenuation and beam's divergence.

The portion across the soft tissue/bone interface is also shown in Fig. 1. The left side from 0 to $z_{b}$, the middle from $z_{b}$ to $z_{c}$, and the right side from $z_{c}$ to $z_{e}$, are regarded as the soft tissue region, the cortical layer, and the spongy/marrow region of bone, respectively. For the following study, the thickness of cortical layer $\left(z_{c}-z_{b}\right)$ and the entire bone thickness $\left(z_{e}-z_{b}\right)$ are set as 0.35 and $6 \mathrm{~cm}$, respectively. The media of soft tissuebone are modeled as liquid-solid and the soft tissue can be considered as liquid due to the contribution of the shear waves to the heating in the soft tissue is negligible (Haken et al 1992). The interface of soft tissue/bone is regarded as a flat boundary, and the relationship between the incident wave and the reflected/refracted waves at the interface can be determined by Snell's law and Mayer (Mayer 1965, Lin et 


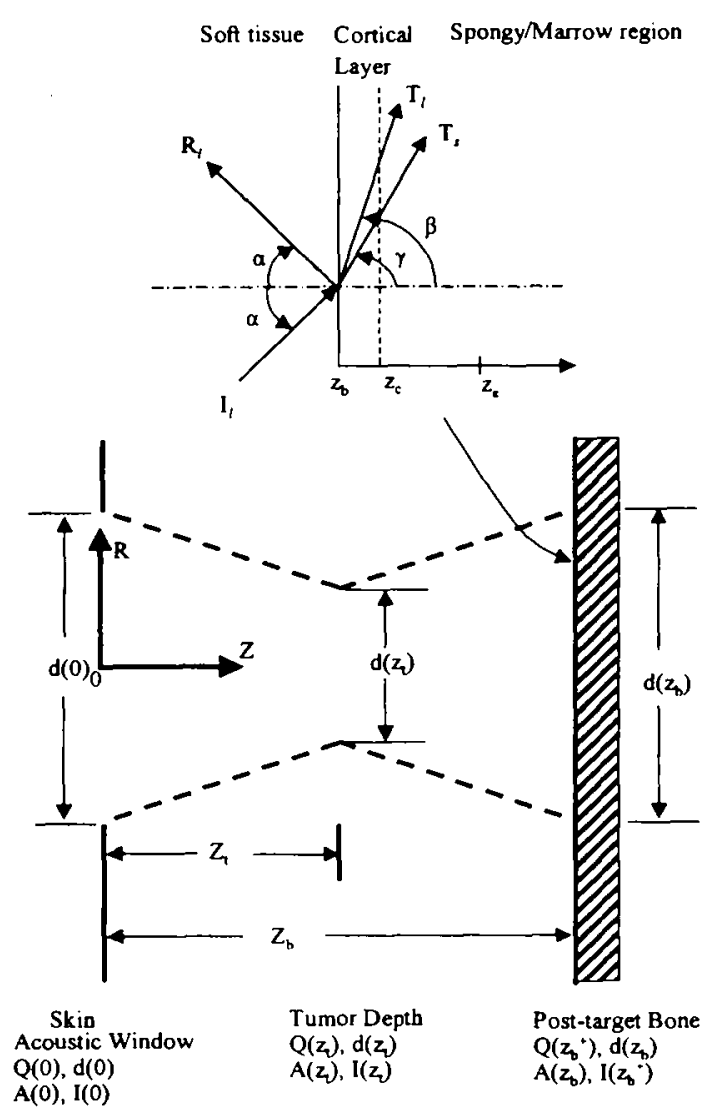

Fig. 1. Schematic diagram of the geometry used in this study. The left side with a diameter of $d(0)$ is the entrance window for the ultrasonic beam. The narrowest region is the focal zone with a diameter of $d\left(z_{t}\right)$ and a distance $z_{t}$ from the acoustic window. The right side with a diameter of $d\left(z_{b}\right)$ is considered as the post-target bone region for the ultrasound beam projecting on. The thickness of the post-target bone is assumed to be $6 \mathrm{~cm}$ during the simulation calculation. The portion across the interface of soft tissue/bone is also shown. The ultrasound beam impinges against the soft tissue/bone interface at a distance of $z_{b}$. The cortical layer is from $z_{b}$ to $z_{c}$ and the spongy/marrow region from $z_{c}$ to $z_{e}, \alpha, \beta$, and $\gamma$ are the angles of the incident longitudinal wave $\left(I_{l}\right)$, refracted longitudinal wave $\left(T_{l}\right)$, and refracted shear wave $\left(T_{s}\right)$, respectively.

al 2000), which are related to the velocities of waves in tissues and the tissue densities. The acoustic and tissue properties used in this study are shown in Table $I$. The total ultrasound energy is attenuated according to the exponential law and the deposition of ultrasonic intensity within the conical region is assumed as a uniform distribution at each depth (Moros et al 1990, Lin et al 1992) to avoid overly complicated calculations.
Then, the ultrasonic intensity on the cross-section area of the cone at depth $z \mathrm{~m}$ is,

For $0 \leq z<z_{b}$ (the soft tissue):

$$
I(z)=\frac{Q(0)}{A(z)} \cdot\left[e^{-2 \mu_{-} / z}+R \cdot e^{-2 p_{-} /\left(2 z_{b}-z\right)}\right]
$$

For $z_{b} \leq z \leq z_{e}$ (the post-target bone):

$$
I(z)=\frac{Q(0)}{A(z)} \cdot e^{-2 \mu_{-} / z_{z}} \cdot\left[(1-R) \cdot S \cdot e^{-2 u_{w} /\left(z-z_{0}\right)}+(1-R) \cdot(1-S) \cdot e^{-2 / z_{z} /\left(z-z_{0}\right)}\right]
$$

$$
\begin{aligned}
\text { with } A(z) & =\pi\left[\frac{d(z)}{2}\right]^{2} \text {, and } \\
d(z) & =d\left(z_{1}\right)+\left[d(0)-d\left(z_{1}\right)\right] \cdot \frac{\left|z-z_{1}\right|}{z_{1}}
\end{aligned}
$$

Where $I(z)$ denotes the ultrasound intensity at depth $z$ $Q(0)$ denotes the total power propagating through the acoustic window, $A(0)=\pi[d(0) / 2]^{2} ; d(0)$ is the diameter of acoustic window; $A(z)$ represents the crosssection area of the cone at depth $z, A(z)=\pi[d(z) / 2]^{2}$; $z_{t}$ and $z_{b}$ are the depths of the tumor and the post-target bone, respectively; $\mu_{b l}, \mu_{b s}$ and $\mu_{m}$ are the ultrasound attenuations coefficients of the refracted longitudinal and shear waves in the bone, and of the longitudinal wave in the soft tissue, respectively; $f$ denotes the ultrasound frequency; $R,(1-R)(1-S),(1-R) S$ are the energy ratios of the reflected longitudinal wave, refracted longitudinal wave, and refracted shear wave to the incident longitudinal wave at the interface of the soft tissue/bone, respectively; $S$ and (1-S) are the energy ratios of the refracted shear and longitudinal waves to the total transmitted wave into the bone, respectively.

Assuming that the ultrasound intensities are not large enough to cause wave distortion and that the attenuation and absorption coefficients for tissues are equal (all of the attenuated energy is absorbed in the heating field (Hynynen 1990)), then the SAR (specific absorption rate) in homogeneous and uniformly attenuating media is proportional to the ultrasound intensity. Hence, we can obtain the absorbed power density at the depth of $z$ as,

For $0 \leq z<z_{b}$ :

$q(z)=2 \alpha \cdot I(z)=2 \mu_{m} f \cdot \frac{Q(0)}{A(z)} \cdot\left[e^{-2 \mu_{a} / z}+R \cdot e^{-2 \mu_{m} /\left(2 z_{b}-z\right)}\right]$

For $z_{b} \leq z \leq z_{e}$ :

$$
q(z)=\frac{Q(0)}{A(z)} \cdot e^{-2 \mu_{\infty} / z_{D}} \cdot\left[\begin{array}{c}
2 \mu_{\infty} f \cdot(1-R) S \cdot e^{-2 \mu_{\infty} f\left(z-z_{D}\right)}+ \\
2 \mu_{\infty} f \cdot(1-R)(I-S) \cdot e^{-2 \mu_{N} f\left(z-z_{b}\right)}
\end{array}\right]
$$


Table I. Nominal values of acoustic and tissue parameters used in this study [thermal and tissue properties (Chato 1985, Gordon et al 1976, Sekins and Emery 1982), acoustic attenuation (Wu and Cubberley 1997)]:

\begin{tabular}{lccccc}
\hline & $\begin{array}{c}\text { Therma } \\
\text { conductivity } \\
\left(\mathrm{W} \mathrm{m}^{-10} \mathrm{C}^{-1}\right)\end{array}$ & $\begin{array}{c}\text { Density } \\
\left(\rho_{m}, \rho_{b}\right)\left(\mathrm{kg} \mathrm{m}^{-3}\right)\end{array}$ & $\begin{array}{c}\text { Blood } \\
\text { perfusion }(W) \\
\left(\mathrm{kg} \mathrm{m}^{-3} \mathrm{~s}^{-1}\right)\end{array}$ & $\begin{array}{c}\text { Velocity } \\
\left(v_{m}, v_{b l}, v_{b s}\right) \\
\left(\mathrm{m} \mathrm{s}^{-1}\right)\end{array}$ & $\begin{array}{c}\text { Attenuation coeff. } \\
\left(\mu_{m}, \mu_{b l}, \mu_{b s}\right) \\
\left(\mathrm{Np} \mathrm{m}^{-1} \mathrm{MHz}^{-1}\right)\end{array}$ \\
\hline Soft tissue & 0.55 & 1050 & 2 & $v_{m}=1500$ & $\mu_{m}=5$ \\
Bone & & & $v_{b l}=3600$ & $\mu_{b l}=86.3$ \\
& 2.3 & 1700 & 0 & $v_{b s}=1800$ & $\mu_{b s}=126.6$ \\
(Cortical) & 0.58 & 1300 & 0.1 & & \\
(Spongy/marrow) & & & & & \\
\hline
\end{tabular}

where $q(z)$ is the absorbed ultrasound power density at the depth $z ; \alpha$ is the ultrasonic absorption coefficient of the tissue $\left(=\mu_{m} f\right.$ for the soft tissue, $=\mu_{b s} f$ or $=\mu_{b l} f$ for the refracted shear and longitudinal waves in the bone, respectively).

Hence, the ratio of $S A R$ at the depth $z$ to the acoustic window area is,

For $0 \leq z<z_{b}$ :

$S R(z, 0)=\frac{q(z)}{q(0)}=\frac{2 \mu_{m} f \cdot \frac{Q(0)}{A(z)} \cdot\left[e^{-2 \mu_{m} / z}+R \cdot e^{-2 \mu_{m} /\left(2 z_{b}-z\right)}\right]}{2 \mu_{m} f \cdot \frac{Q(0)}{A(0)} \cdot\left[1+R \cdot e^{-4 \mu_{m} / z_{b}}\right]}$$$
=\left[\frac{d(0)}{d(z)}\right]^{2} \cdot \frac{e^{-2 \mu_{G} / z}+R \cdot e^{-2 \mu_{m} f\left(2 z_{b}-z\right)}}{1+R \cdot e^{-\mu_{m} / z_{b}}}
$$

For $z_{b} \leq z \leq z_{e}$ :
$S R\left(z_{1}, 0\right)=\frac{q\left(z_{t}\right)}{q(0)}=\left[\frac{d(0)}{d\left(z_{t}\right)}\right]^{2} \cdot \frac{e^{-2 \mu_{-} / z_{t}}+R \cdot e^{-2 \mu_{m} f\left(z_{\left.z_{b}-z_{t}\right)}\right.}}{1+R \cdot e^{-4 H_{m} \int z_{b}}}$

and

$$
d\left(z_{t}\right)=\frac{\sqrt{\frac{e^{-2 \mu_{m} f z_{t}}+R \cdot e^{-2 \mu_{m} f\left(2 z_{b}-z_{t}\right)}}{1+R \cdot e^{-4 \mu_{m}} \overline{f z_{b}}}}}{\sqrt{S R\left(z_{t} ; 0\right)}} \cdot d(0)
$$

where $S R\left(z_{i} ; 0\right)$ is the ratio of $S A R$ of ultrasound at the tumor depth to that at the acoustic window area, $\operatorname{SAR}\left(z_{t}\right) / \operatorname{SAR}(0)$.

By considering the post-target bone, we can derive the ratio of $S A R$ at the tumor depth $z_{t}$ to the post-target bone surface $z_{b}$ as,

$$
S R\left(z_{1} ; z_{0}^{\prime}\right)=\frac{q\left(z_{1}\right)}{q\left(z_{0}^{*}\right)}
$$

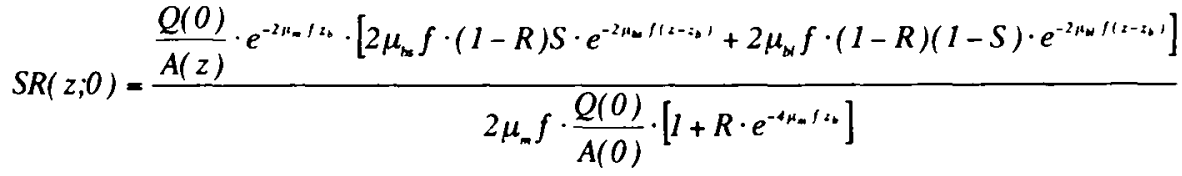

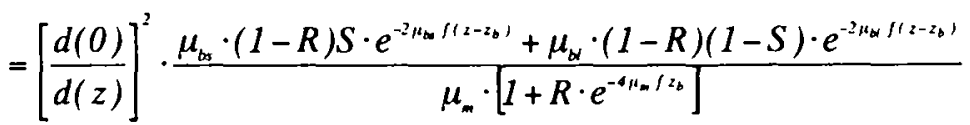

where $S R(z ; 0)$ is the ratio of specific absorption rate $(S A R)$ of ultrasound at the depth $z$ to the acoustic window area, $\operatorname{SAR}(z) / \operatorname{SAR}(0) ; q(0)$ denotes the absorbed ultrasound power density on the acoustic window.

Equations (3a-b) are used to calculate the distribution of the $S A R$ ratio in the ultrasound power deposition region. From Equation (3a), we can obtain

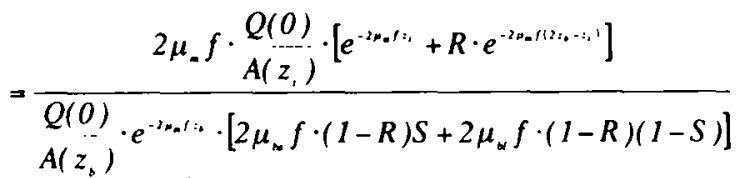

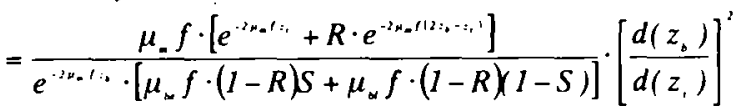


Rearranging Equation (6) with

$$
d\left(z_{b}\right)=d\left(z_{1}\right)+\left[d(0)-d\left(z_{1}\right)\right] \cdot \frac{z_{b}-z_{1}}{z_{1}} \text { (from the }
$$

geometry), we can obtain

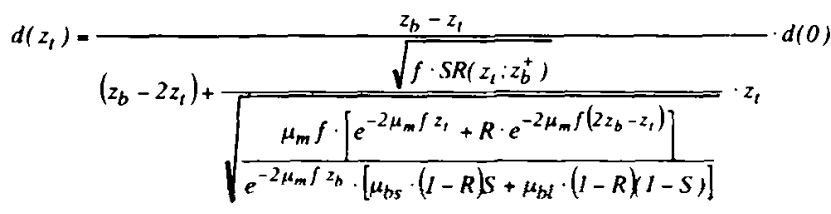

\subsection{Temperature Solver}

Pennes (1948) steady-state bio-heat transfer equation (BHTE) was used to solve for the temperature distribution,

$$
k \nabla^{2} T-W c_{b}\left(T-T_{a}\right)+q=0
$$

Even though the simplified BHTE neglects the effects of blood vessels and the redistribution of thermal energy within the local vascular network, it is still a good approximation for modeling bio-thermal processes (Arkin et al 1994, Rocmer 1990, Chato 1990) and performing general parameter studies. For convenience, this bio-heat transfer equation can also be written in other forms (Nyborg 1988, NCRP 1992) to provide a better description of the heat transfer in the tissue. We select the thermal properties to approximate averages for soft tissue and bone tissue (Chato 1985, Gordon et al 1976, Sekins and Emery 1982 ), and the values are shown in Table I. The absorbed ultrasonic power density $(q(z))$ was obtained using the above procedure for a given input power $Q(0)$. All attenuated ultrasonic energy was assumed to be absorbed by the tissue in the heating region. The anatomic and physiological properties were assumed to remain constant throughout the entire field, and metabolism was neglected due to its small contribution to the temperature changes (Roemer 1990, Jain 1983). The blood perfusion $(W)$ is maintained at 2,0 , and $0.1 \mathrm{~kg} \mathrm{~m}^{-3} \mathrm{~s}^{-1}$ for the soft tissue, cortical layer, and spongy/marrow bone, respectively, unless otherwise noted. The diameter and the thickness of the cylindrical volume of the simulated tissue were changed their sizes according to the depth of post-target bone, acoustic window, and the tumor depth and tumor size. When the dimension of the acoustic window is close to the simulated tissue's diameter, the radius of simulated tissuc is expanded to avoid the effect of boundary condition. The thickness of post-target bone is $6 \mathrm{~cm}$ for all simulations. The front surface and other boundary conditions were a constant temperature at $37^{\circ} \mathrm{C}$. The central axis was treated as adiabatic (Lin et al 1992) because no energy transfer occurs in the radial direction at the central axis due to the radial symmetry of both the power distribution and the anatomical and physiological properties. The steady-state BHTE was numcrically approximated using the successive-over-relaxation technique and the method of central finite differences (Ferziger 1981) to obtain the two-dimensional temperature field $(r-z)$ induced by the power deposition for a given set of tumor/bone conditions, acoustic window size, and input power level. The grid spacing used is $0.1 \mathrm{~cm}$, the over-relaxation factor is 1.8 , and the convergence criterion is the root mean square error less than $10^{-7}$.

\subsection{Search Algorithm}

The procedure shown in Figure 2 is used to search for the appropriate input power level and the acoustic window size that will result in a temperature distribution to meet the temperature conditions for a given set of tumor/bone conditions. During the search, temperature constraints are employed as the determination conditions for the process. The temperature at the focal zone is set to reach $45^{\circ} \mathrm{C}$, and the greater value be-

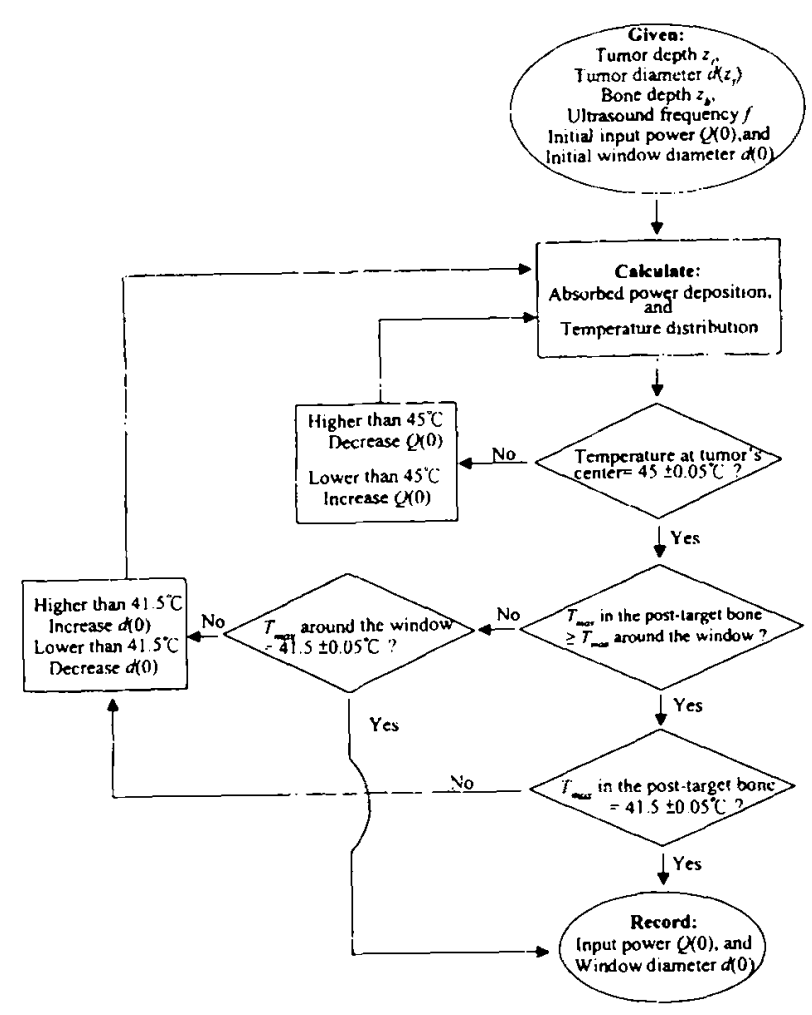

Fig. 2: Flow chart of the search method used to determine the appropriate diameter of the acoustic window and the input power level for a given set of tumor/post-target bone conditions, and ultrasound frequency. The temperature conditions are employed as the constraint criteria to obtain an appropriate temperature distribution. 
Table II. Cases of incident angle and energy partition for the study of SAR ratio and temperature distribution:

\begin{tabular}{cccc}
\hline Case & $\alpha$ & $R$ & $S$ \\
\hline 1 & Ideal & 0.0 & 0.0 \\
2 & $0^{0}$ & 0.35 & 0.0 \\
3 & $20^{0}$ & 0.35 & 0.27 \\
4 & $40^{0}$ & 0.2 & 1.0 \\
5 & $60^{\circ}$ & 1.0 & 0.0 \\
\hline
\end{tabular}

Where $\alpha$ is the angle of incident longitudinal wave at the interface of soft tissue/bone; $R$ is the energy ratio of the reflected longitudinal wave to the incident longitudinal wave; and $S$ is the energy ratio of the refracted shear wave to the total transmitted wave into the bone.

tween the maximum temperature of the region close to the acoustic window and that of the post-target bone is set at $41.5^{\circ} \mathrm{C}$. Those temperature conditions are used to obtain an appropriate input power level and acoustic window size which can raise the maximum temperature of the predetermined region to $45^{\circ} \mathrm{C}$ without overheating the post-target bone and the normal tissue, particularly the region close to the acoustic window.

\section{RESULTS}

To investigate the influence of the incident angle of uitrasound beam at the interface of soft tissue/bone on the distributions of $S A R$ ratio and temperature in the tissues, several representative values listed in Table II have been used. The values in Table II can be determined by Snell's law and Mayer (Mayer 1965, Lin et al 2000), which are functions of the angles of the incident wave and the reflected/refracted waves at the interface of soft tissue/bone and the velocities of waves in tissues and the tissue densities. The acoustic and tissue properties used in this study are shown in Table I. The search method of Fig. 2 is employed for Case 1 in Table II to obtain an appropriate input power level and acoustic window size for heating a 5-cm diameter tumor located at $10 \mathrm{~cm}$ deep and the post-target bone at $20 \mathrm{~cm}$ with an ultrasound frequency of $1 \mathrm{MHz}$. Then this acoustic window size is fixed while the input power level is tuned to have a $T\left(z_{t}\right)=45^{\circ} \mathrm{C}$ for all of the other cases. Figure 3a is the distribution of $S A R$ ratio for those cases in Table II using Equation (3) to calculate and scale the absorbed power deposition in the tissues. The ultrasound attenuation at $1 \mathrm{MHz}$ is $5 \mathrm{~Np} \mathrm{~m}^{-1}$ for soft tissue, and 86.3 and $126.6 \mathrm{~Np} \mathrm{~m}^{-1}$ for the longitudinal and the shear waves in bone, respectively (Wu and Cubberley 1997). The $S A R$ ratio distribution shows that a sharp peak occurs at the interface of soft tissue/bone due to the much greater ultrasound absorption of the bone (refracted longitudinal and/or shear waves). The maximum of these peaks is the peak for
Case 4 , with $20 \%$ of the incident energy reflected and the remainder transmitted into the bone as shear wave. For Case 1, the ultrasound beam penetrates into the bone deeper than the other cases due to a $100 \%$ of the incident energy transmitted into the bone as longitudinal wave. Figure $3 b$, showing the corresponding temperature distribution for Fig. 3a, indicates that the peak temperatures occur in the bone region beyond the interface of soft tissue/bone, instead of at the interface (the location of the peak of SAR ratio). Fig. 3b denotes that the peak temperature is higher for the case with a lower percentage of reflected energy, and hence Case 1 with a $100 \%$ of transmitted energy produces the maximum of the peak temperatures. The assumption of a $100 \%$ of the incident energy transmitted into the bone as longitudinal wave will result in a higher temperature rise in the bone region, while those temperatures in the other regions have trivial changes. Hence the simulation result obtained with the assumption of ultrasound totally penetrating into the post-target bone is the most conservative case for the temperature rise in the post-target bone (Tu et al 1994), when the conditions of the incident angle of ultrasound beam at the interface of soft tissue/bone are not available.

The above study is based on the ultrasound attenuation coefficients of longitudinal and shear waves for bone (Wu and Cubberley 1997) of 86.3 and 126.6 $\mathrm{Np} \mathrm{^{-1 }} \mathrm{MHz}^{-1}$, respectively, and $5 \mathrm{~Np} \mathrm{~m}^{-1} \mathrm{MHz}^{-1}$ for soft tissue. In contrast, other investigators (Goss et al $1978,1979,1980$ ) showed a large range of acoustic attenuation coefficients for bone tissue. The acoustic attenuation coefficient of bone is one of the crucial factors determining the distributions of $S A R$ ratio in tissues. It is necessary to study the influence of this factor on the distributions of $S A R$ ratio and temperature. Figures $4 a-b$ present the results for Case 2 in Table II, when the attenuation coefficient of longitudinal wave for bone is varied from $50,100,150$, to $200 \mathrm{~Np} \mathrm{~m}^{-1}$ $\mathrm{MHz}^{-1}$ with the other conditions maintained the same as those for Figs. 3a-b. Fig. 4a indicates that a greater attenuation coefficient of longitudinal wave in bone re- 

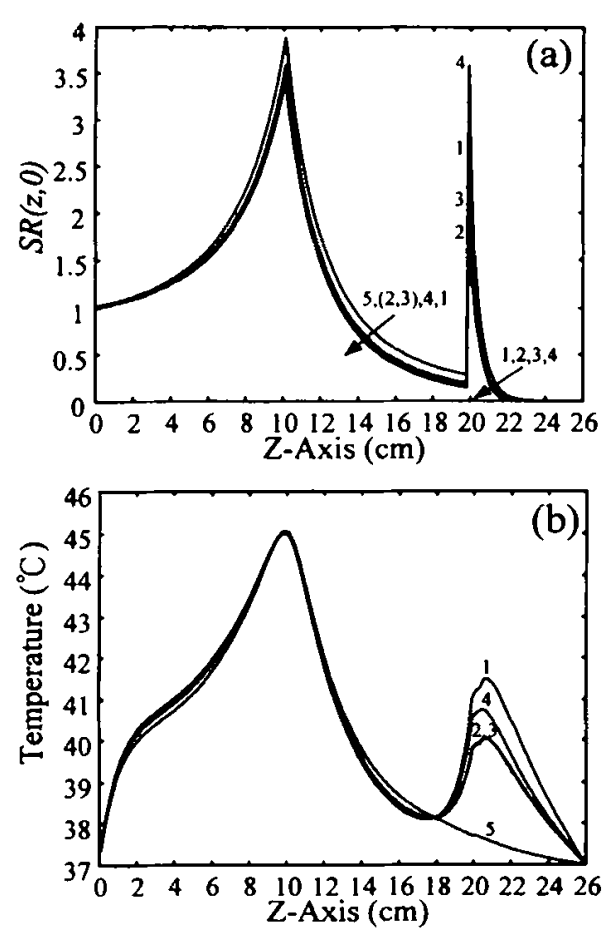

Fig. 3 Distributions of $S A R$ ratio $(S R(z ; 0))$ and temperature in the tissues for the cases in Table II, with an ultrasound frequency of $1 \mathrm{MHz}$. The interface of soft tissue/bone is located at $20 \mathrm{~cm}$.

sults in a higher peak of $S A R$ ratio at the interface of soft tissue/bone, while for a lower one the ultrasound beam penetrates deeper into the bone. The corresponding temperature distribution shown in Fig. $4 \mathrm{~b}$ reveals that for a greater attenuation coefficient the peak temperature shifts closer to the interface of soft tissue/bone. However, the differences of all peak temperatures are not significant due to the temperature elevation contributed by a higher absorbed power density is compensated by the greater conduction. The temperature results indicate that a greater acoustic attenuation coefficient of bone results in a peak temperature closer to the interface of soft tissue/bone, with the temperature mainly determined by the percentage of the ultrasound energy transmitted into the bone.

Figures 5a shows the temperature distributions along the depth direction for ultrasound frequency from 0.4 to $2.2 \mathrm{MHz}$ when employing the search method of Fig. 2 to obtain an appropriate input power level and acoustic window size for heating a $5-\mathrm{cm}$ diameter tumor located at $10 \mathrm{~cm}$ deep and the post-larget bone at $20 \mathrm{~cm}$. The blood perfusion $(W)$ is 2,0 , and 0.1 $\mathrm{kg} \mathrm{m}^{-3} \mathrm{~s}^{-1}$ for the soft tissue, cortical layer, and spongy/marrow bone, respectively. A $100 \%$ of the incident energy transmitted into the bone as longitudinal wave $(R=S=0)$ is assumed. This figure reveals that the
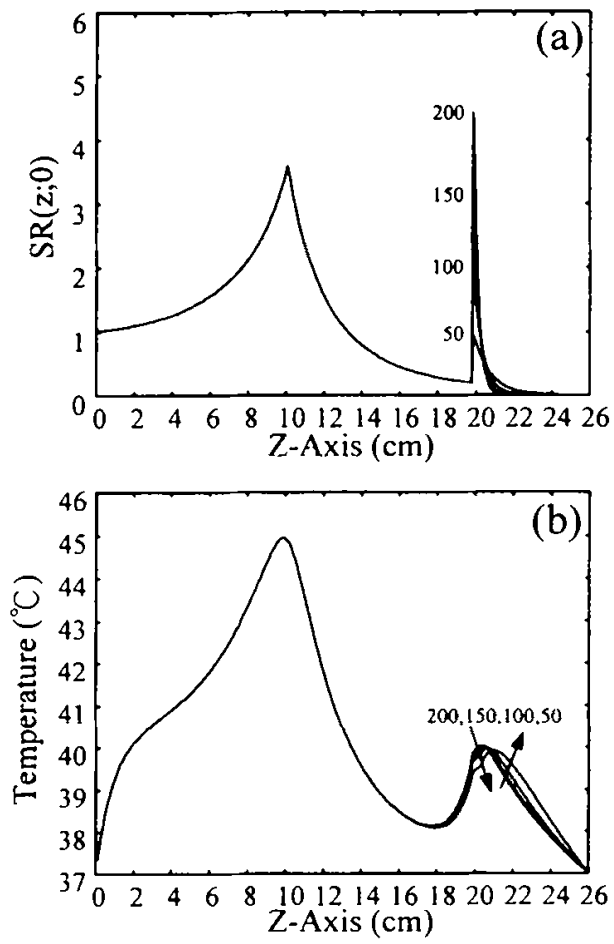

Fig. 4 Effect of acoustic absorption coefficient in bone on the distributions of $S A R$ ratio and temperature. The energy partition of Case 2 in Table II is used and the ultrasound attenuation for the refracted longitudinal wave $\left(\mu_{b t}\right)$ of bone is equal to $50,100,150$, or 200 $\mathrm{Np} \mathrm{\textrm {m } ^ { - 1 }} \mathrm{MHz}^{-1}$, while the other conditions maintained the same as those in Fig. 3.

temperature rise in the post-target bone decreases but the rise close to the acoustic window increases when a higher frequency ultrasound is used. A higher frequency ultrasound attenuates faster in the tissues and hence a greater amount of energy is absorbed to produce a higher tempcrature rise in the region close to the acoustic window. On the other hand, a lower frequency ultrasound attenuates slower and is able to penetrate deeper to produce a higher temperature rise in the post-target bone. Figure $5 \mathrm{~b}$ presents the relationship between $S R\left(z_{i} ; 0\right), f \cdot S R\left(z_{i} ; z_{b}^{+}\right)$and ultrasound frequency corresponding to Fig. 5a, based on Equations (4) and (6) for both $R$ and $S$ equal to 0 . The curves show the variations of $S R\left(z_{i} ; 0\right)$ and $f \cdot S R\left(z_{t} ; z_{b}^{+}\right)$to the frequency when appropriate temperature distributions are obtained using the search method of Fig. 2. The value of $S R\left(z_{i} ; 0\right)$ decreases monotonously with ultrasound frequency and then maintains about a constant value, while $f \cdot S R\left(z_{i} ; z_{b}^{+}\right)$ firstly maintains about a constant value in the low frequency range and then increases monotonously. When comparing with the temperature distributions in Fig. 5a, Fig. 5b shows that the constraint condition for the left 

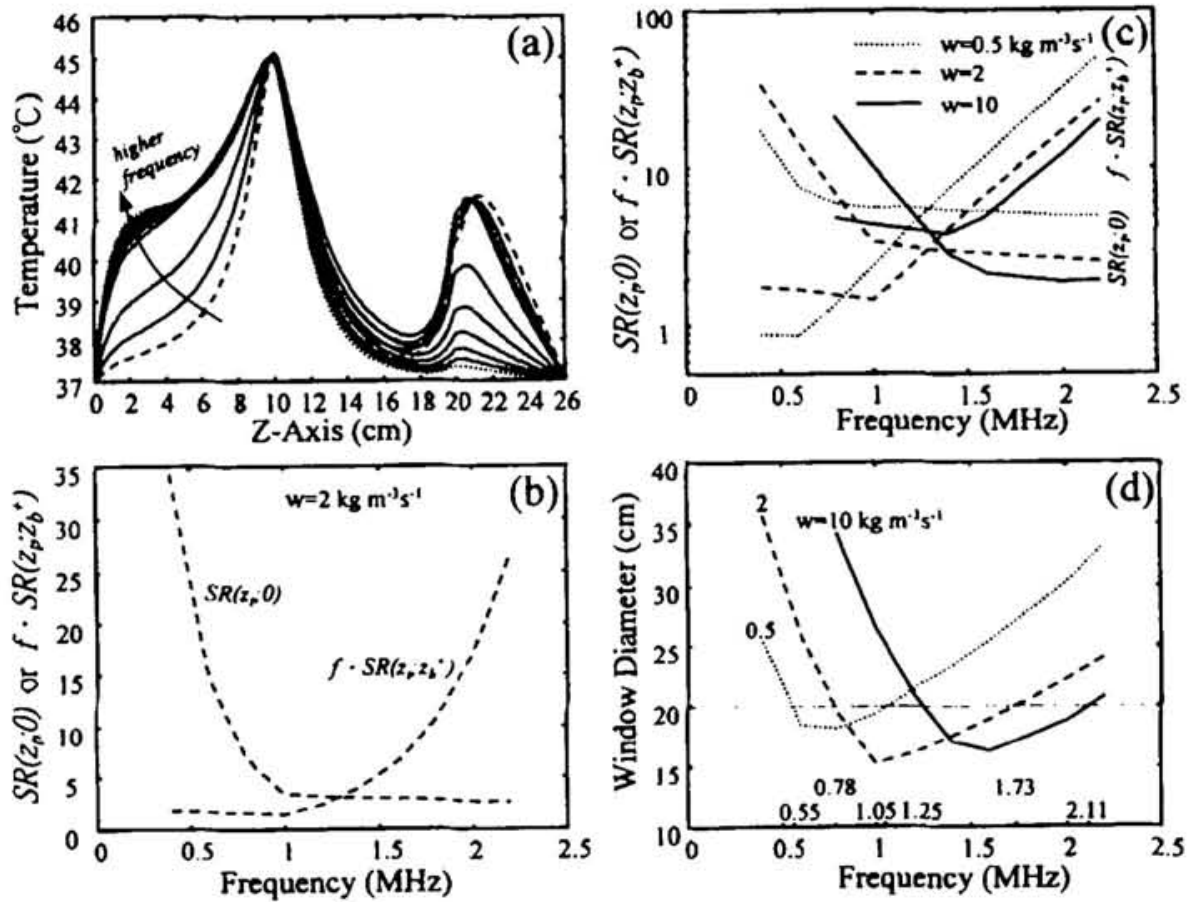

Fig. 5 (a) Temperature distributions obtained from the search method of Fig. 2 for $z_{t}=10 \mathrm{~cm}, d\left(z_{t}\right)=5 \mathrm{~cm}, z_{t}$ $=20 \mathrm{~cm}, R=S=0$, and $W=2 \mathrm{~kg} \mathrm{~m}^{-3} \mathrm{~s}^{-1}$ (blood perfusion) for the soft tissue, while different ultrasound frequencies are used; (b) relationship between $S R\left(z_{t} ; 0\right), f \cdot S R\left(z_{f} ; z_{b}^{+}\right)$and ultrasound frequency $(f)$ corresponding to (a); (c) relationship between $S R\left(z_{t} ; 0\right), f \cdot S R\left(z_{t} ; z_{b}^{+}\right)$and $f$ for the blood perfusion of soft tissue from 0.5 to $10 \mathrm{~kg} \mathrm{~m}^{-3} \mathrm{~s}^{-1}$, while the other conditions maintained the same as (a); (d) relationship between the acoustic window size and ultrasound frequency determined by the search method of Fig. 2.

side is the overheating of the post-target bone caused by low-frequency ultrasound, while the right side denotes that the constraint condition is the overbeating of the region close to the acoustic window caused by high-frequency ultrasound. Figure 5 b indicates the low bounds of $S R\left(z_{t} ; 0\right)$ and $f \cdot S R\left(z_{t} ; z_{b}^{+}\right)$for obtaining an appropriate temperature distribution when an external ultrasound hyperthermia is used for treating a tumor in front of a bone. Low-frequency ultrasound can penetrate deeper to cause an overbeating in the post-target bone and hence a low bound of $f \cdot S R\left(z_{t} ; z_{b}^{+}\right)$is required, while a low bound of $\operatorname{SR}\left(z_{t} ; 0\right)$ is needed for high-frequency ultrasound to avoid an over-high temperature problem in the region close to the acoustic window.

Fig.5c presents the variations of $S R\left(z_{i} ; 0\right)$ and $f \cdot S R\left(z_{t} ; z_{b}^{+}\right)$to ultrasound frequency when appropriate temperature distributions are obtained using the search method of Fig. 2 for the same tumor/bone conditions as those in Figs. 5a-b except the blood perfusion of soft tissue varied from 0.5 to $10 \mathrm{~kg} \mathrm{~m}^{-3} \mathrm{~s}^{-1}$. Similar phenomenon of the change of the values of $S R\left(z_{i} ; 0\right)$ and $f \cdot S R\left(z_{t} ; z_{b}^{*}\right)$ from monotonous decrease to a constant value (or from a constant value to monotonous increase) can be seen as those in Fig. 5b, while the change appears in the lower frequency region $(\sim 0.6 \mathrm{MHz})$ for $0.5 \mathrm{~kg} \mathrm{~m}^{-3} \mathrm{~s}^{-1}$ and in the higher frequency region $(\sim 1.5 \mathrm{MHz})$ for $10 \mathrm{~kg} \mathrm{~m}^{-3} \mathrm{~s}^{-1}$. Figure $5 \mathrm{~d}$ depicts the relationship between the required acoustic window size and ultrasound frequency when the search method of Fig. 2 is used for the same tumor/bone conditions, while the blood perfusion varied from 0.5 to $10 \mathrm{~kg} \mathrm{~m}^{-3} \mathrm{~s}^{-1}$. During this search, the tumor/bone conditions are fixed and the search outputs are the required acoustic window size $(d(0))$ and the input power level $(Q(0))$, which are varied to meet the temperature conditions for different ultrasound frequencies. The results show that a minimum of the required acoustic window sizes appears for each blood perfusion curve that fulfills the temperature conditions, and the corresponding ultrasound frequency can be called as the optimal frequency for each blood perfusion case. The curves also reveal that the optimal frequency increases with the blood perfusion. This finding suggests that a higher ultrasound frequency should be used for a greater blood perfusion to overcome the difficulty of the high acoustic absorption of post-target bone. Those curves also show that a range of frequen- 
cies can be used to meet the temperature requirements for the same tumor/bone conditions with a greater acoustic window size. For instance, the range of ultrasound frequency is from 0.78 to $1.73 \mathrm{MHz}$ for the case of $2 \mathrm{~kg} \mathrm{~m}^{-3} \mathrm{~s}^{-1}$ when a $20 \mathrm{~cm}$ acoustic window size is used. For this case, an overheating in the post-target bone appears if a frequency lower than $0.78 \mathrm{MHz}$ is used. On the other hand, the overheating occurs in the region close to the acoustic window for a frequency higher than $1.73 \mathrm{MHz}$.

Fig. 5c shows the low bounds of $f \cdot S R\left(z_{t} ; z_{b}^{+}\right)$ and $S R\left(z_{i} ; 0\right)$ for low- and high-frequency ultrasound and their values are about 2 and 3 , respectively, for the case with the blood perfusion of soft tissue $2 \mathrm{~kg} \mathrm{~m}^{-3} \mathrm{~s}^{-1}$ This indicates that we can analyze the relationship between the tumor/bone conditions $\left(z_{t}, d\left(z_{t}\right), z_{b}\right)$ and the control parameters $(d(0), f)$ based on both $f \cdot S R\left(z_{t} ; z_{b}^{+}\right)$and $S R\left(z_{t} ; 0\right)$. Equation (5) presents the relationship between $d(0), f, z_{t}, d\left(z_{t}\right), z_{b}$ and $S R\left(z_{i} ; 0\right)$, while Equation (7) is for $f \cdot S R\left(z_{t} ; z_{b}^{+}\right)$. Equations (5) and (7) are then employed to investigate the domain formed by treatable tumor size and tumor depth when a set of control parameters and the depth of posttarget bone are given. Figure 6a, obtained from Equations $(5)$ and $(7)$ with $S R\left(z_{t} ; 0\right)=3, f \cdot S R\left(z_{t} ; z_{b}^{+}\right)=2$, $z_{b}=20 \mathrm{~cm}$, and $f=1 \mathrm{MHz}$, displays the relationship between the treatable tumor size and tumor depth which meets the requirements of both $S R\left(z_{t} ; 0\right) \geq 3$ and $f \cdot S R\left(z_{t} ; z_{b}^{+}\right) \geq 2$ for acoustic window size from 10 to $25 \mathrm{~cm}$. The region within each acoustic window curve is the domain formed by treatable tumor sizes and tumor depths. This finding suggests that a tumor whose size and depth located within this domain is treatable by using an ultrasound frequency of $1 \mathrm{MHz}$ for the post-target bone located at $20 \mathrm{~cm}$. Figure $6 \mathrm{a}$ also indicates the minimum size of acoustic window
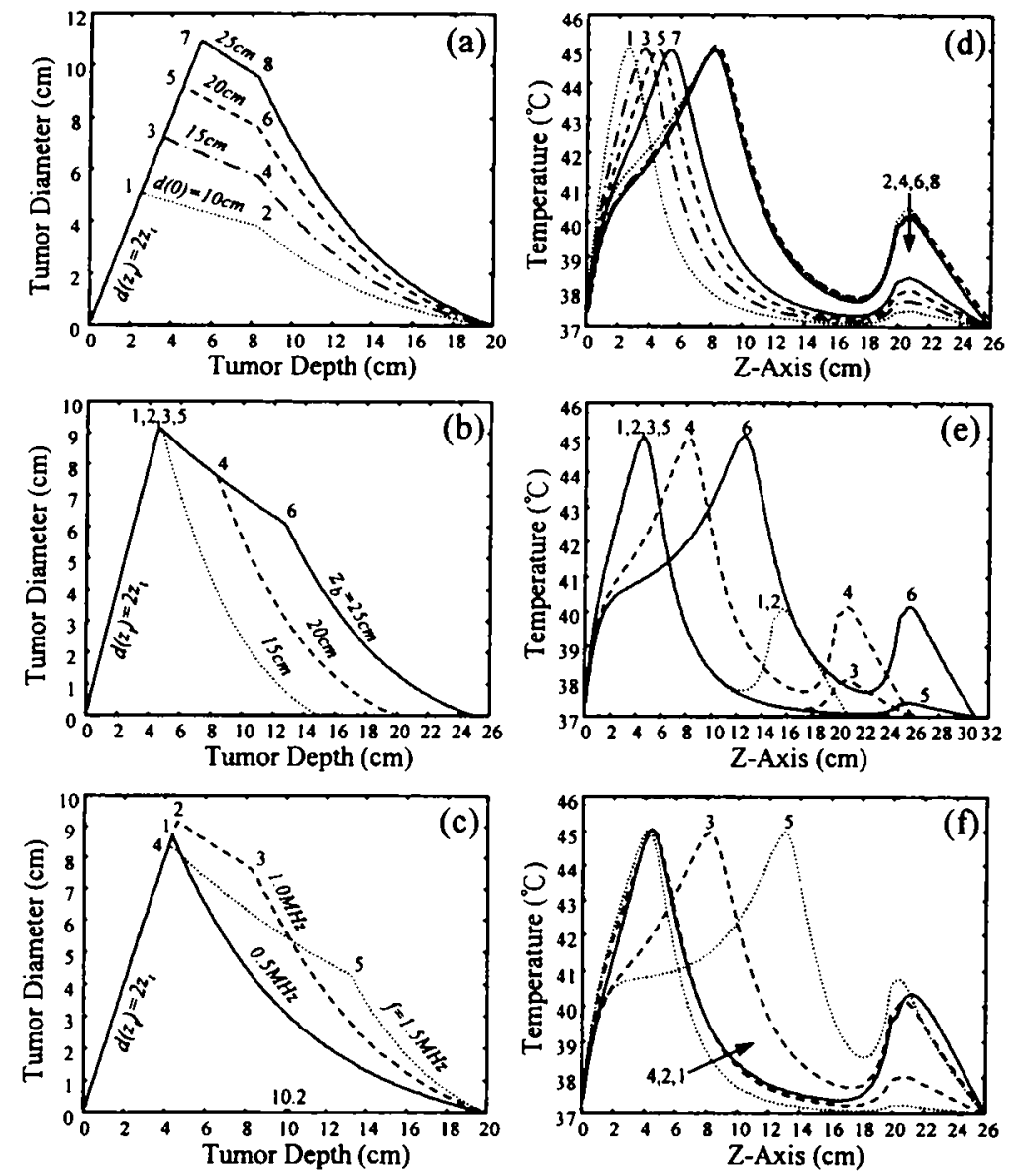

Fig. 6 Domain of treatable tumor size and tumor depth determined by Eqs. (5) and (7), which meet the re. quirements of both $S R\left(z_{t} ; 0\right) \quad 3$ and $f \cdot S R\left(z_{t} ; z_{b}^{+}\right) \quad 2$, for $R=S=0 ;$ (a) $f=1 \mathrm{MHz}, z_{b}=20 \mathrm{~cm}$, while $d(0)$ varied from 10 to $25 \mathrm{~cm}$; (b) $f=1 \mathrm{MHz}, d(0)=20 \mathrm{~cm}$, while $z_{b}$ located at from 15 to $25 \mathrm{~cm}$; and (c) $d(0)=20 \mathrm{~cm}, z_{b}=20$ $\mathrm{cm}$, while $f$ varied from 0.5 to $1.5 \mathrm{MHz}$. (d-f) Temperature distributions for points 1.8 in (a), points $1-6$ in (b), and points $1-5$ in (c), respectively. 
required to be chosen for a given set of tumor size and tumor depth. For a spherical tumor, the tumor center location and the tumor size are also required to meet the line, $d\left(z_{t}\right)=2 z_{t}$, which means the tumor depth is equal to the tumor radius. This finding suggests that the center of spherical tumor must be located within the house-like domain to be treated using the given acoustic window size.

Figure $6 \mathrm{~b}$ shows the effect of the depth of posttarget bone on the domain of treatable tumor size and tumor depth. The post-target bone is located at 15, 20, or $25 \mathrm{~cm}$, and the acoustic window size is $20 \mathrm{~cm}$, while the other conditions are maintained the same as those in Fig. 6a. Similar to the study of the effect of acoustic window size, a deeper post-target bone results in a larger treatable domain covering the one for a shallower post-target bone. Figure $6 \mathrm{c}$ depicts the effect of ultra-
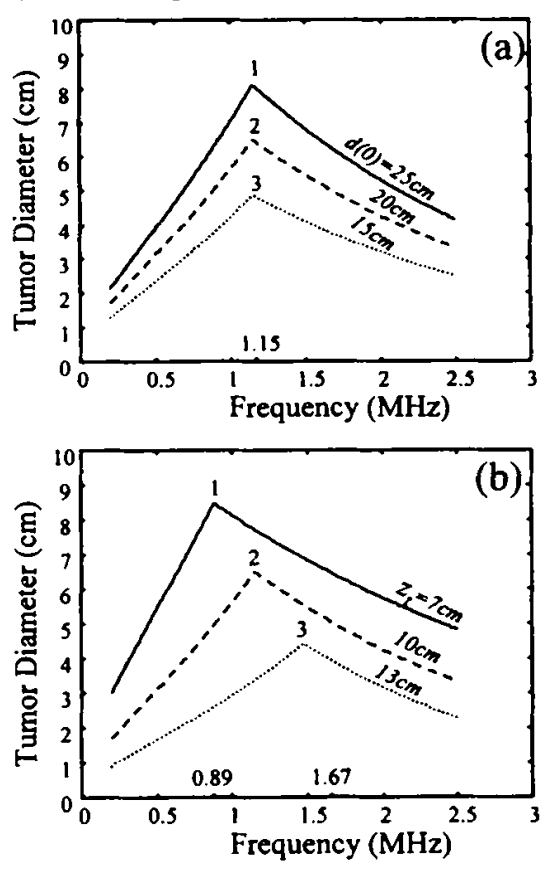

(b)

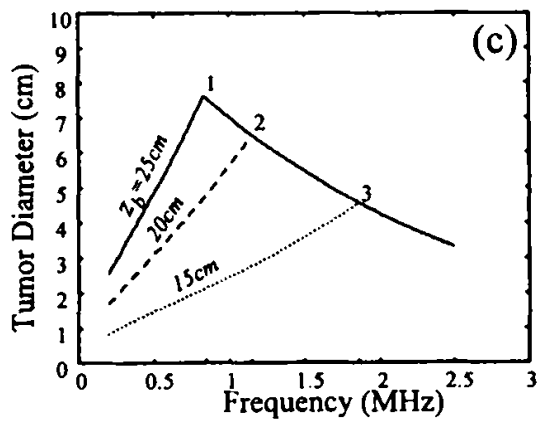

sound frequency on the domain of treatable tumor size and tumor depth for an acoustic window size of $20 \mathrm{~cm}$, and the other conditions are maintained the same as those in Fig. 6a. All of the curves show that the treatable tumor diameter decreases with tumor depth. Unlike the acoustic window study, a larger acoustic window owns a larger treatable domain covering that owned by a smaller acoustic window, a higher frequency ultrasound does not own a larger treatable domain. Instead, these curves are a kind of mixture. The curve for $1 \mathrm{MHz}$ owns the largest treatable tumor size for tumor depth shallower than $10.2 \mathrm{~cm}$, the curve for 1.5 $\mathrm{MHz}$ denotes the tumor which is located deeper than $10.2 \mathrm{~cm}$, while the curve for $0.5 \mathrm{MHz}$ does not show its advantage for heating any tumor depth due to the easy cause of high temperature in the post-target bone. The temperature distributions for points 1-8 in
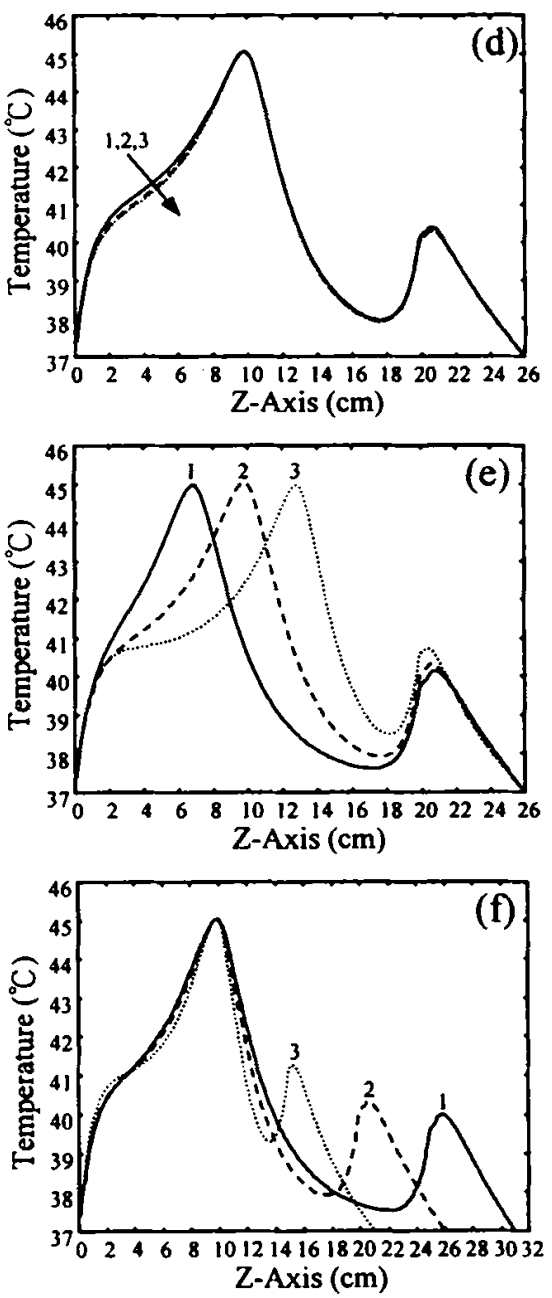

Fig. 7 Relationship between the treatable tumor size and ultrasound frequency obtained from Eqs. (5) and (7), which meet the requirements of both $S R\left(z_{t} ; 0\right)=3$ and $f \cdot S R\left(z_{t} ; z_{b}^{+}\right)=2$, for $R=S=0 ;(a) f=1 \mathrm{MHz}, z_{t}=10$ $\mathrm{cm}, z_{b}=20 \mathrm{~cm}$, while $d(0)$ varied from 10 to $25 \mathrm{~cm}$; (b) $f=1 \mathrm{MHz}, d(0)=20 \mathrm{~cm}$, while $z_{t}$ located at from 7 to 13 $\mathrm{cm}$; (c) $f=1 \mathrm{MHz}, d(0)=20 \mathrm{~cm}, z_{t}=10 \mathrm{~cm}$, while $z_{b}$ located at from 15 to $25 \mathrm{~cm}$. (d-f) Temperature distributions for points $1-3$ in (a-c), respectively. 
Figs. 6a, points 1-6 in Fig. $6 \mathrm{~b}$, and points $1-5$ in Fig. $6 \mathrm{c}$ are shown in Figs. 6d, 6e, and 6f, respectively. All temperature distributions fulfill the requirements, demonstrating that Eqs. (5) and (7), which are based on the $S A R$ ratios and frequency, can be used to analyze the domain of treatable tumor size and tumor depth when appropriate values of $S R\left(z_{i} ; 0\right)$ and $f \cdot S R\left(z_{t} ; z_{b}^{+}\right)$are given.

Figure $7 \mathrm{a}$ depicts the relationship between the treatable tumor size and ultrasound frequency when Equations (5) and (7) are employed for a tumor located at $10 \mathrm{~cm}$ deep, the post-target bone at $20 \mathrm{~cm}$, and $S R\left(z_{t} ; 0\right)=3, f \cdot S R\left(z_{t} ; z_{b}^{+}\right)=2$, with acoustic window sizes from 15 to $25 \mathrm{~cm}$. This figure shows that a peak of treatable tumor size appears for each acoustic window curve. This peak indicates the maximum treatable tumor size that fulfills both $S R\left(z_{t} ; 0\right) \geq 3$ and $f S R\left(z_{1} ; z_{b}^{*}\right) \geq 2$, and the corresponding ultrasound frequency is called the optimal frequency. Hence, the optimal frequency is the one to be used to obtain the maximum treatable tumor size when the acoustic window size, the tumor depth and the depth of post-target bone are given. The curves mentioned above also reveal that the optimal frequency, maintained at 1.15 $\mathrm{MHz}$, is independent of the acoustic window size. Figure $7 \mathrm{~b}$ provides the results revealing that the optimal frequency increase with the tumor depth when Equations (5) and (7) are used for an acoustic window size of $20 \mathrm{~cm}$ and the tumor located at 7,10 or $13 \mathrm{~cm}$, while the other condition are maintained the same as those in Fig. 7a. This finding suggests that a higher ultrasound frequency should be used for a deeper tumor to overcome the difficulty of the high acoustic absorption of post-target bone. This finding seems to be in contrast with the conventional concept that a lower ultrasound frequency should be used for heating a deeper tumor when the post-target bone does not exist (Hynynen 1990). Those curves in Fig. 7b also show that a range of frequencies can be used to meet the requirements for a tumor located at the same depth but smaller than the maximum treatable tumor size. For instance, the range of frequency is from 0.89 to 1.67 $\mathrm{MHz}$ for a $5-\mathrm{cm}$ diameter tumor located at $10 \mathrm{~cm}$ deep. For this case, an overheating in the post-target bone appears if a frequency lower than $0.89 \mathrm{MHz}$ is used. On the other hand, the overheating occurs in the region close to the acoustic window for frequency higher than $1.67 \mathrm{MHz}$. Figure 7c shows the results for an acoustic window size of $20 \mathrm{~cm}$ and the other condition maintained the same as those in Fig. $7 \mathrm{a}$, while the posttarget bone is located at 15,20 , or $25 \mathrm{~cm}$. This figure indicates that the optimal ultrasound frequency increases for a shallower post-target bone. Comparing Fig. $7 b$ and $7 c$, it denotes that a shallower post-target bone has the similar influence on the optimal frequency as a deeper tumor. The temperature distributions for those critical points of Figs. 7a-c are shown in
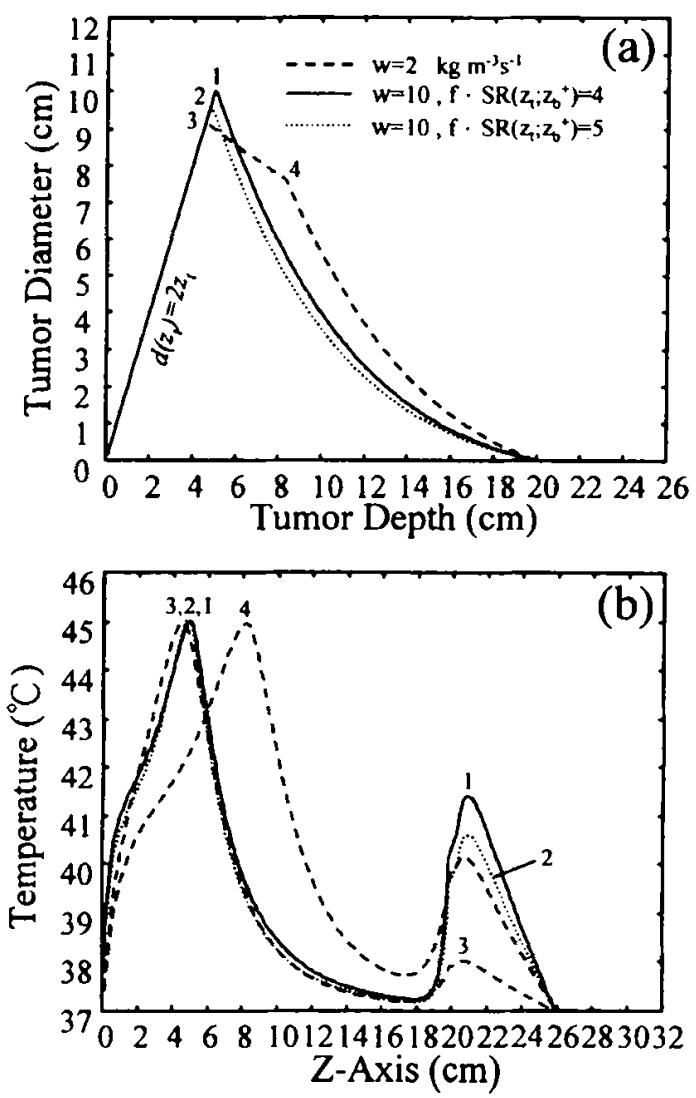

Fig. 8 Effect of blood perfusion of soft tissue on the domain of treatable tumor size and tumor depth, (a) $S R\left(z_{t} ; 0\right) 2$ and $f \cdot S R\left(z_{t} ; z_{b}^{+}\right) 4$ (or 5$)$ for $10 \mathrm{~kg}$ $\mathrm{m}^{-3} \mathrm{~s}^{-1}$, and $S R\left(z_{t} ; 0\right) \quad 3$ and $f \cdot S R\left(z_{1} ; z_{b}^{+}\right) 2$ for 2 $\mathrm{kg} \mathrm{m}^{-3} \mathrm{~s}^{-1}$, while the other conditions maintained the same as those in Fig. 6b. (b) Temperature distributions for points 1-4 in (a).

Figs. 7d-f, respectively. The temperature distributions for the optimal cases in Fig.7a show that there is only a small temperature variation in the post-target bone and in the region close to the acoustic window. The temperature peak in the post-target bone gets greater for a decper tumor (Fig. 7e) and for a shallower post-target bone (Fig. 7f). All temperature distributions fulfill the requirements, demonstrating that Eqs. (5) and (7) can be used to analyze the optimal frequency and the treatable tumor size when appropriate values of $S R\left(z_{t} ; 0\right)$ and $f \cdot S R\left(z_{1} ; z_{b}^{+}\right)$are given.

\section{DISCUSSION AND CONCLUSION}

The above study is based on a conical shape of convergent/divergent power deposition that would result in a disk-shaped region with temperature higher than $43 \mathrm{C}$. To form a conformal power deposition for the tumor shape to meet the treatment requirement, 
multiple scan planes located at different depths with suitable power weighting can be used. Through adjusting the power weighting, a quite uniform $S A R$ ratio distribution within the tumor region and a sharp drop of the ratio outside the tumor region can be obtained. Additionally, the input power level can be tuned to have the maximum temperature at the predetermined tumor region to reach the desired temperature. When the blood perfusion of soft tissue is a time-varying unknown during the hyperthermia treatment, feedback control algorithms (Chen et al 1999, Hutchison et al 1998) can be employed to compensate for this factor. However the low bounds of $S R\left(z_{t} ; 0\right)$ and $f \cdot S R\left(z_{t} ; z_{b}^{+}\right)$, which are the key factors of the relationship between the tumor conditions $\left(z_{t}, d\left(z_{t}\right), z_{b}\right)$ and the control parameters $(d(0), f)$ as shown in equations (5) and (7), are functions of blood perfusion (Fig. 5c). Hence the control parameters are also necessary to be simultaneously varied to meet the requirement.

Figure 8a shows the treatable domain for the blood perfusion of soft tissue equal to $10 \mathrm{~kg} \mathrm{~m}^{-3} \mathrm{~s}^{-1}$, while the low bounds of $\operatorname{SR}\left(z_{i} ; 0\right)$ and $f \cdot \operatorname{SR}\left(z_{t} ; z_{b}^{+}\right)$ are taken from Fig. $5 c$ as 2 and 4 (or 5) with the other conditions maintained the same as those in Fig. $6 \mathrm{~b}$. Comparing this result with that for $2 \mathrm{~kg} \mathrm{~m}^{-3} \mathrm{~s}^{-1}$ (also shown in Fig. 8a), it indicates that the treatable domain for a higher blood perfusion shrinks to the left side and the condition of Equation (7) becomes more dominant (for $10 \mathrm{~kg} \mathrm{~m}^{-3} \mathrm{~s}^{-1}$, the condition of Equation (5) disappears). The corresponding temperatures of the critical points in Fig. 8a are shown in Figure 8b, denoting that the temperature elevation in the post-target bone is higher for $10 \mathrm{~kg} \mathrm{~m}^{-3} \mathrm{~s}^{-1}$ and it can be effectively reduced by selecting a greater value of $f \cdot S R\left(z_{t} ; z_{b}^{+}\right)$, which results in a smaller treatable domain (as shown in Fig. 8a).

Owing to the difference of the acoustic impedance of soft tissue and bone, part of the acoustic energy is reflected back to the soft tissue when the ultrasound beam propagates through the interface of soft tissue and bone. This reflection will result in less ultrasound energy penetrating into the bone, and hence the peaks of $S A R$ ratio at the interface and the temperature in the bone region are significantly reduced while there are trivial changes in the other regions. Furthermore, the ultrasound wave was assumed to transmit smoothly through the second interface (cortical layer/spongy bone) in the above study and Equation (2b), which neglects the effect of the second interface, was used to describe the absorbed power deposition in the bone region $\left(z_{b} \leq z \leq z_{e}\right)$. When the second interface considered as a sharp change in acoustic impedance and normal incidence for the ultrasound beam, the absorbed power density in the bone region is,

For $z_{b} \leq z<z_{c}$ (cortical layer):

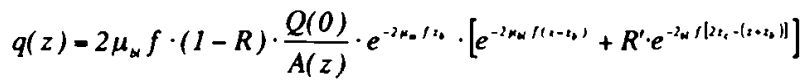

For $z_{c} \leq z \leq z_{e}$ (spongy/marrow region):

$q(z)-2 \mu_{b l} f \cdot(1-R) \cdot \frac{Q(0)}{A(z)} \cdot e^{-2 \mu_{-} f z_{b}} \cdot e^{-2 \mu_{W} /\left(x_{z}-z_{b}\right)} \cdot\left[\left(1-R^{\prime}\right) \cdot e^{-2 \mu_{W} f\left(z-z_{t}\right)}\right]$

$R^{\prime}$ is the energy ratio of the reflected wave to the incident wave at the second interface and can be obtained by the densities of cortical layer and spongy/marrow region and the acoustic velocities in the cortical layer and the spongy/marrow region (Mayer 1965, Lin et al 2000). $R^{\prime}$ is about equal to 0.12 for a $2300 \mathrm{~m} / \mathrm{s}$ acoustic velocity in the spongy bone and the other parameters are shown in Table 1 . The resulting $S A R$ ratio in the cortical layer is higher $3.6 \%$ at $z_{b}^{+}$(the interface of muscle/cortical layer) and $12 \%$ at $z_{c}^{-}$(the interface of cortical layer/spongy bone) than those without considering the second reflection, while the $S A R$ ratio in the spongy/marrow region decreases $12 \%$. Hence the location of maximum temperature rise in the bone may shift from the spongy/marrow region to the cortical layer for a sharp change of acoustic impedance at the second interface.

Equation (5) and Equation (7) are employed to study the interrelationship between the control parameters $(d(0), f)$ and the tumor/post-target bone conditions $\left(z_{t}, d\left(z_{t}\right), z_{b}\right)$. The values of $S R\left(z_{t} ; 0\right)$ in Eq. (5) and $f \cdot S R\left(z_{i} ; z_{b}^{+}\right)$in Eq. (7) are determined in Fig. 5c, which is based on the temperature distributions obtained by a search algorithm, and the low bounds of $S R\left(z_{t} ; 0\right)$ and $f \cdot S R\left(z_{t} ; z_{b}^{+}\right)$are functions of blood perfusion. The results obtained by using Equations (5) and (7) with suitable low bounds of $S R\left(z_{\xi} ; 0\right)$ and $f \cdot S R\left(z_{t} ; z_{b}^{+}\right)$demonstrate how to select an appropriate ultrasound frequency (Figs. $7 \mathrm{a}-\mathrm{c}$ ) and the size of acoustic window (Fig. 7a) required to produce a good treatment for a specific set of tumor/bone conditions. In addition, Figs. 6a-c indicate the domain of treatable tumor size and tumor depth for a given set of control parameters and the depth of post-target bone. Findings of this study can be used as a guideline to design an appropriate ultrasound heating system for a specific treatment needs, to know whether or not a tumor is treatable, as well as to select a suitable frequency for ultrasound transducer and the minimum acoustic win- 
dow size required for the system arrangement to meet the treatment requirements when the tumor size/tumor depth together with the depth of post-target bone are known from clinical treatment.

\section{ACKNOWLEDGMENTS}

The authors would like to thank the National Science Council of the Republic of China for partially supporting this research under Contract No. NSC 892213-E-002-043.

\section{REFERENCES}

1. Arkin $H, X u X$, and Holmes $\mathrm{K}$ R: Recent developments in modeling heat transfer in blood perfusion tissues IEEE Trans. Biomed. Eng. 1994; 41: 97-107

2. Cain $C A$, and Umemura $S$ : Concentric-ring and sector vortex phased array applicators for ultrasound hyperthermia therapy IEEE Trans. Microwave Theory Tech. 1986; 34: 542-551

3. Cain C A, Umemura S, Ibbini M, and Ebbini E 1987 Ultrasound phased array hyperthemria applicators Proc. 9th IEEE/EMBS Meeting pp 1640-1641

4. Chato J C 1985 Selected thermophysical properties of biological materials in Heat Transfer in Medicine and Biology, Analysis and Applications 1985, ed A Shitzer and R C Eberhart (New York: Plenum) pp 413-418

5. Chato J C 1990 Fundamentals of bio-heat transfer in Thermal Dosimetry and Treatment Planning1990, ed M Gautherie (Berlin: Springer) pp 1-56

6. Chen Y-Y, Lin W-L, Liou H-L, Yen J-Y, and Shieh M-J: Self-tuning fuzzy logic control for ultrasound hyperthermia with reference temperature based on objective function Med. Phys. 1999; 26: 825-833

7. Davis B J, and Lele P P 1987 Bone-pain during hyperthermia by ultrasound Proc. 35th Ann. Meeting Rad. Research Soc. p 11

8. Diederich C J, Stauffer P R, Sneed P K, and Phillips T L 1992 A temperature simulation study of the deep heating capabilities of a rotating multitransducer ultrasound hyperthermia system Proc. 6th Int. Cong. on Hyperthermic Oncology p 346

9. Dutton A W, Roemer R B, and Gibbs F A 1996 A clinically integrated scanned focused ultrasound hyperthermia Proc. 7th Int. Cong. Hyperthermic Oncology vol 1, p 92.

10. Ferziger J H 1981 Numerical Methods for Engineering Applications (New York: Wiley)

11. Fessenden P, Lee E R, Anderson T L, Strohbehn J W, Meyer J L, Samulski T V, and Marmor J R: Experience with a multi-transducer ultrasound system for localized hyperthermia of deep tissues IEEE Trans. Biomed. Eng. 1984;31:126-135
12. Frizzell L A, and Carstensen E: Shear properties of mammalian tissues at low megahertz frequencies $J$. Acoust. Soc. Am. 1976;60:1409-1411

13. Gordon R G, Roemer R B, and Horvath S M: A mathematical model of the human temperature regulatory system - transient cold exposure response IEEE Trans. Biomed. Eng. 1976;23: 434444

14. Goss S A, Johnson R L, and Dunn F: Comprehensive compilation of empirical ultrasonic properties of mammalian tissues J. Acoust. Soc. Am. $1978 ; 64: 423-457$

15. Goss S A, Frizzell L A, and Dunn F: Ultrasonic absorption and attenuation of high frequency sound in mammalian tissues Ultrasound Med. Biol. 1979;5:181-186

16. Goss S A, Johnson R L, Dunn F: Compilation of empirical ultrasonic properties of mammalian tissues, Il J. Acoust. Soc. Am. 1980;68:93-108

17. Haken B A, Frizzell L A, and Carstensen E L: Effect of mode conversion on ultrasonic heating at tissue interfaces J. Ultrasound Med. 1992;11:393405

18. Hunt J W, Lockwood G, and Worthington A: Design of conical transducers to produce strongly focused ultrasound beams for deep heating Int. J. Hyperthermia 1991;7:15-28

19. Hutchison E, Dahleh M, and Hynynen K: The feasibility of MRI feedback control for intracavitary phased array hyperthermia treatments Int. J. Hyperthermia 1998; 14:39-56

20. Hynynen K, Watmough D J, Shammari M, Wilmot G, Murthy M S N, Mallard J R, Fuller M, and Sarkar T 1983 A clinical hyperthermia unit utilizing an array of seven focused ultrasonic transducers Proc. IEEE Ultrasound Symp. pp 816-821

21. Hynynen $K$, Roemer R B, Anhalt D, Johnson C, Xu Z-X, Swindell W, and Cetas T: A scanned focused multiple transducer ultrasonic system for localized hyperthermia treatments Int. J. Hyperthermia 1987;3:21-35

22. Hynynen $K$, and DeYoung D: Temperature elevation at muscle-bone interface during scanned, focused ultrasound hyperthermia Int. J. Hyperthermia 1988;4:267-279

23. Hynynen K 1990 Biophysics and technology of ultrasound hyperthermia in Methods of External $\mathrm{Hy}$ perthermic Heating 1990 ed M Gautherie (Berlin: Springer) pp 61-116

24. Jain R K 1983 Bio-heat transfer: mathematical models of thermal systems in Hyperthermia Cancer Therapy 1983, ed F K Storm (Boston: Hall) pp 946

25. Lehmann J F, deLateur B J, and Silverman D R: Selective heating effects of ultrasound in human being Arch. Phys. Med. Rehab. 1966;47:331-339

26. Lchmann J F, deLateur B J, Warren C G, and 
Stonebridge J S: Heating produced by ultrasound in bone and soft tissue Arch. Phys. Med. Rehab. 1967; $48: 397-401$

27. Lele P P, and Parker K J: Temperature distributions in tissues during local hyperthermia by stationary or steered beams of unfocused or focused ultrasound British J. Cancer 1982;45 (Suppl. V): $108-121$

28. Lele P P 1984 Ultrasound: is it the modality of choice for controlled, localized heating of deep tumors ? in Hyperthermia Oncology 1984 vol. 2, ed J Overgaard (London: Taylor and Francis) pp 129154

29. Lele P P 1989 Advanced ultrasonic techniques for local tumor hyperthermia in The Radiologic Clinics of North America: Hyperthermia 1989 vol 27, ed R A Steeves (Philadelphia: W B Saunders) pp. 559575.

30. Lin W-L, Roemer R B, Moros E G, and Hynynen $\mathrm{K}$ : Optimization of temperature distributions in scanned, focused ultrasound hyperthermia Int. J. Hyperthermia 1992;8:61-78

31. Lin W-L, Chen Y-Y, Lin S-Y, Yen J-Y, Shieh M-J, and Kuo T-S: Optimal configuration of multiplefocused ultrasound transducers for external hyperthermia Med. Phys. 1999a;26: 2007-2016

32. Lin W-L, Yen J-Y, Chen Y-Y, Jin K-W, and Shieh M-J: Relationship between acoustic aperture size and tumor conditions for external ultrasound hyperthermia Med. Phys. 1999b;26: 818-824

33. Lin W-L, Liauh C-T, Chen Y-Y, Liu H-C, and Shieh M-J: Thoretical study of temperature elevation at muscle/bone interface during ultrasound hyperthermia Med. Phys. 2000;27: 1131-1140

34. Moros E G, Roemer R B, and Hynynen K: Prefocal plane high temperature regions induced by scanning focused ultrasound beams Int. J. Hyperthermia 1990;6:351-366

35. Marmor J B, Pounds D, Postic T B, and Hahn G M: Treatment of superficial human neoplasms by local hyperthermia induced by ultrasound Cancer 1979;43:188-197

36. Mayer W G: Energy deposition of ultrasonic waves at flat boundaries Ultrasonics 1965;3: 62-68

37. McGough R J 1996An optimal heating strategy for deep hyperthermia with ultrasound phased arrays Proc. 7th Int. Cong. Hyperthermic Oncology vol 2, pp 564-567

38. NCRP Report No. 113, 1992 Exposure Criteria for Medical Diagnostic Ultrasound: I. Criteria based on the Thermal Mechanisms1992, (MD: NCRP Publication, ) pp 52-60

39. Nelson P A, Herrick J F, and Krusen F H: Temperature produced in bone marrow, bone and adjacent tissues by ultrasound diathermy Arch. Phys. Med. 1950;31:687-695

40. Nyborg W L: Solutions of the bio-heat transfer equation Phys. Med. Biol. 1988;33:785-792

41. Pennes H H: Analysis of tissue and arterial blood temperatures in the resting human Forearm J. Appl. Physiol. 1948;1:93-122

42. Roemer R B 1990 Thermal dosimetry in Thermal Dosimetry and Treatment Planning 1990, ed M Gautherie (Berlin: Springer) pp 119-214

43. Sekins K M, and Emery A F 1982 Thermal science for physical medicine in Therapeutic Heat and Cold 1982, ed J F Lehmann (Baltimore: Williams and Wilkins) pp 70-132

44. Seppi E, Shapiro E, Zitelli L, Henderson S, Wehlau A, Wu G, and Dittmer C 1985 A large aperture ultrasonic array system for hyperthermia treatment of deep-seated tumors Proc. IEEE Ultrasound Symp. pp 942-949

45. Svensson G K, Hansen J L, Carpini D D, Bornstain B, and Herman T 1992 SAR and temperature distributions from a spherical focused, segmented ultrasound machine Proc. 6th Int. Cong. on Hyperthermic Oncology p 335

46. Tu S-J, Hynynen K, and Roemer R B: Simulation of bi-directional ultrasound hyperthermia treatments of neck tumors Int. J. Hyperthermia 1994; 10:707-722

47. Wu J, and Cubberley F: Measurement of velocity and attenuation of shear waves in bovine compact bone using ultrasonic spectroscopy Ultrasound Med. Biol. 1997;23:129-134 